\title{
HETEROGENEOUS CATALYSIS IN SUSTAINABLE GREEN SOLVENT: ALKENES HYDROGENATION WITH NEW SILICA IMMOBILIZED PALLADIUM COMPLEX CONTAINING S,O-CHELATING LIGAND
}

\author{
Filiz YILMAZ * \\ Chemistry Department, Science Faculty, Anadolu University, Eskişehir, Türkiye
}

\begin{abstract}
$\mathrm{Pd}(\mathrm{II})$ complex containing S,O-chelating ligand was immobilized on surface of the amine functionalized silica support in $\mathrm{scCO}_{2}$ media. Silica-based catalyst $\left(\mathrm{SiO}_{2}\right.$-ThiophPd(II)) was characterized by IR, SEM, XRF, and BET analyses. The catalytic activity of the immobilized catalyst in hydrogenation reactions of alkenes has been compared with the homogeneous counterpart. $\mathrm{SiO}_{2}-$ ThiophPd(II) catalyst showed good activity and reusability than homogeneous system. The best conversion in styrene hydrogenation was obtained with TOF value as $5871 \mathrm{~h}^{-1}$ at $370 \mathrm{~K}, 10$ bar $\mathrm{H}_{2}$ and 1500 psi total pressure. Especially, while homogeneous counterpart has not activity in cyclohexene hydrogenation, it has been provided $100 \%$ cyclohexane conversion with the immobilized catalyst. It has also been found that the catalyst can be reused at least ten times without significant loss of activity in the styrene hydrogenation.
\end{abstract}

Keywords: Immobilized Pd(II) complex, Alkene Hydrogenation, Reusability, Supercritical carbon dioxide

\section{INTRODUCTION}

Catalysts have become an important component of the chemical industry. Selectivity and reusability of catalysts are one of the most important parameters for catalytic reactions [1-3]. Homogeneous catalysts being in the same phase with substrates and products have high activity and selectivity advantage under mild reaction conditions $[4,5]$. Due to the fact that homogeneous catalysts are molecularly dispersed in the reaction media, separation and reusability problems of the catalyst is major drawback in these systems [6,7]. A solution of these problems is immobilization of homogeneous catalysts on an inert support material [5, 8, 9]. There are many different kinds of support material such as silica, alumina, organic polymers or dendrimers. $\mathrm{SiO}_{2}$ is an irreducible oxide and often preferred in heterogeneous catalysis due to its high surface area $\left(<100 \mathrm{~m}^{2} \mathrm{~g}^{-1}\right)$, chemical and thermal stability $[10,11]$.

One of the most important disadvantages of synthetic chemistry is the harmful effects of organic solvents. Removal of solvents from the reaction products causes both energy consumption and time loss. These drawbacks can be solve using sustainable green solvents instead of organic solvents [12]. Sustainable green solvents are supercritical carbon dioxide, ionic liquids, water, and fluorinated solvent [13-16]. Among them, supercritical carbon dioxide $\left(\mathrm{scCO}_{2}\right)$ have lower viscosity and higher diffusivity than liquids, which allows high separation efficiencies [17, 18]. These features increase mass transfer rates in $\mathrm{scCO}_{2}$ and many substances can be dissolve better than gases in $\mathrm{scCO}_{2}[19]$. The physicochemical properties of $\mathrm{scCO}_{2}$ such as viscosity, density, dielectric constant and permeability can be adjusted by pressure and temperature change. $\mathrm{scCO}_{2}$ is a suitable reaction solvent for heterogeneous chemical reactions [20, 21]. Using $\mathrm{scCO}_{2}$ as a solvent in heterogeneous reactions instead of organic solvents contributes of heterogeneous catalysis existing advantages. The high diffusivity and low viscosity of $\mathrm{scCO}_{2}$ allow the substrates to reach the active sites on the surface of catalyst, better than liquid solvents. Also, $\mathrm{scCO}_{2}$ has a zero surface tension [22]. This provides a good wetting of the surface for chemical reactions on the surface and allows a better

*Corresponding Author: fyilmaz@anadolu.edu.tr

Receiving Date: 26 March 2018 Publishing Date: 29 June 2018 
penetration of the reactants into a porous structure. The separation of $\mathrm{scCO}_{2}$ from the products at the end of reaction is easy and the products can be obtained as dry and pure [23].

In this study, the previously reported homogeneous $\mathrm{Pd}$ (II)-complex containing perfluoroalkylated $\mathrm{S}, \mathrm{O}$ ligand was immobilized on silica support. The catalytic activity of immobilized catalyst was tested in hydrogenation reactions of some alkenes. Immobilization process of complex and activity tests were performed in $\mathrm{scCO}_{2}$ medium. Styrene, 1-octene and cyclohexene were used as substrate and hydrogenation of these alkenes performed using $\mathrm{H}_{2}(\mathrm{~g})$.

\section{EXPERIMENTAL}

\subsection{Materials}

Reagents and standards used in syntheses and catalytic studies were purchased and used without purification. Organic solvents were used after purification and drying. Thiophene-2-carbonyl chloride 1H,1H-perfluoro-1-nonanol, palladium(II) acetylacetonate (Aldrich), 3-Aminopropyl triethoxysilane (APTES) were acquired from Aldrich. Triethylamine, 1-octene, silica gel were supplied by Merck. Styrene and cyclohexane were purchased from Fluka, immobilization of homogeneous complex and catalytic hydrogenation reactions were carried out high pressure reactor (Parr inst. $100 \mathrm{~mL}$ stainless steel reactor including magnetic stirrer and temperature controller). The IR spectra were recorded using $\mathrm{KBr}$ pellets between 400 and $4000 \mathrm{~cm}^{-1}$ on a Perkin Elmer Spectrum 100 Spectrometer. The morphology of immobilized catalyst observed with Carl Zeiss Ultra Plus FESEM SEM. Surface area and pore size distrubition analysis of catalyst was carried out on a Quantachrome Nova 2200e BET instrument. Pore size distribution was determined using density functional theory (DFT). The conversion rates and product distributions were determined by gas chromatography (Thermo Finnigan Trace GC) equipped with a capillary column (Permabond column (SE-54-DF-0.25, $25 \mathrm{~m}$ x0.32 mm i.d.).

\subsection{Immobilization of homogeneous catalyst in $\mathrm{scCO}_{2}$ media}

Homogeneous Pd(II)-complex, ThiophPd(II), containing perfluoroalkylated S,O ligand was prepared by the method given in the literature [24]. The surface of silica was modified with amino group by a silanization reaction before the homogeneous catalyst was immobilized on to the silica support. To modify the surface of silica, $\mathrm{SiO}_{2}$ suspension $(3.15 \mathrm{~g}$ in $250 \mathrm{~mL}$ dry toluene) and APTES (2.5 mL) were refluxed at $95^{\circ} \mathrm{C}$ with stirring for $24 \mathrm{~h}$. Obtained amino-functionalized silica defined as $\mathrm{SiO}_{2}-\mathrm{APTES}$ was collected by centrifugation and washed with methanol $(2 \times 30 \mathrm{~mL})$ and then transferred to a Soxhlet extractor and washed with dichloromethane for $4 \mathrm{~h}$. $\mathrm{SiO}_{2}$-APTES was dried in a vacuum oven at $100{ }^{\circ} \mathrm{C}$ for $6 \mathrm{~h}$. For the immobilization of homogeneous catalyst, $\mathrm{SiO}_{2}-\mathrm{NH}_{2}(300 \mathrm{mg})$ and homogeneous $\mathrm{Pd}(\mathrm{II})$ complex $(20 \mathrm{mg})$ were charged into the reactor. The reactor was closed and heated to $70{ }^{\circ} \mathrm{C}$ and $\mathrm{CO}_{2}$ gas was pressurized to the reactor. Total pressure of reactor was 1500 psi. After 2 hours, the reactor was colled and depressurized to atmospheric condition and immobilized catalyst ( $\mathbf{S i O}_{2}$ - ThiophPd(II)) was obtained as dry and pure. Preparation method and possible structure of $\mathrm{SiO}_{2}-\mathrm{ThiophPd}(\mathrm{II})$ catalyst were given in Figure 1.

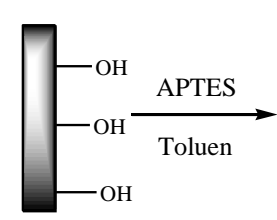

$\mathrm{SiO}_{2}$

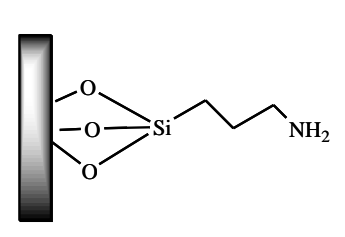

$\mathrm{SiO}_{2}$-APTES

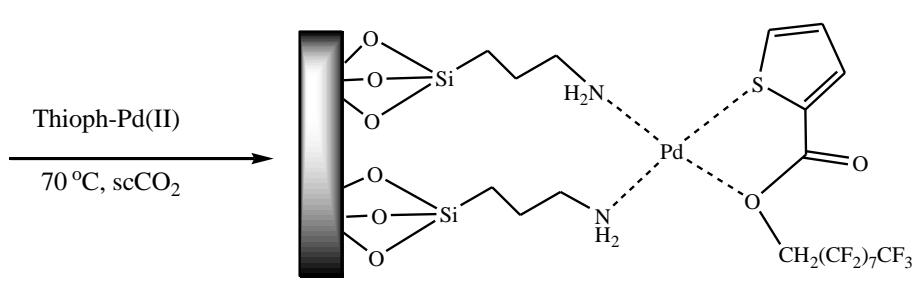

$\mathrm{SiO}_{2}$-ThiophPd(II)

Figure 1. Preparation method of the immobilized homogeneous catalyst 


\subsection{Catalytic Hydrogenation Studies in $\mathrm{scCO}_{2}$ Media}

$100 \mathrm{~mL}$ high pressure reactor (Parr Inc. 4590 micro Bench Top having digital temperature controller and stirrer) was used for the catalytic hydrogenation in $\mathrm{scCO}_{2}$ media. Substrat and catalyst were added to the reactor. The reaction vessel was sealed and flushed three times with $\mathrm{CO}_{2}$ at 5 bar. $\mathrm{The}_{2} \mathrm{H}_{2}$ gas was pressurized onto the reactor at room temperature and then reactor was heated to the desired temperature. At this temperature, $\mathrm{CO}_{2}$ was pressurized onto the reactor via a syringe pump (Isco Inc. Model 260D). The samples were collected in hexane at specific time intervals. At the end of reaction, system was cooled and depressurized with valves. The sample solution was directly analyzed by gas chromatography and conversion percentage of product was determined with GC.

The effectiviness of the catalyst was expressed as turn over number (TON) and can be defined as:

$$
\text { TON }=\frac{(\text { Number of moles of substrate })(\% \text { Conversion })}{(\text { Number of moles of catalyst }}
$$

The term turnover frequency (TOF) employed to study the reaction rate can be defined as:

$$
\text { TOF }=\frac{\text { TON }}{\text { Time }}
$$

\section{RESULTS}

\section{1. Characterization}

Characterization studies of homogeneous Pd(II)-complex have been detailed in the previous study [24]. The immobilized catalyst prepared in this study was characterized by various techniques such as, FTIR, Far-IR, XRF, SEM, SEM-EDX and BET. In the FT-IR spectra of silica, Si-O and O-H bands were observed at 1092 and $3436 \mathrm{~cm}^{-1}$ respectively. The peak observed at $2937 \mathrm{~cm}^{-1}$ in IR spectra of immobilized catalyst is related with aliphatic $\mathrm{C}-\mathrm{H}$ stretching vibration bands of propyl chain of APTES group bonded to silica surface. Also, the peak correspond to aromatic $\mathrm{C}=\mathrm{C}$ bond in thiophene ring was observed at $1564 \mathrm{~cm}^{-1}$. In the Far-IR spectra of immobilized catalyst, Pd-S and Pd-O stretching vibrations were observed at $295.94 \mathrm{~cm}^{-1}$ and $265.22 \mathrm{~cm}^{-1}$. These peaks indicate that the homogeneous complex is immobilized to the silica surface.

Structural composition of immobilized catalyst was determined by XRF method. XRF analysis results show that $60.9,21.02,0.3$ and $2.36 \%$ of oxygene, silicon, sulphur and palladium are present respectively in $5 \mathrm{mg} \mathrm{SiO}{ }_{2}$-ThiophPd(II) sample. The existence of sulphur and palladium proves that the ThiophPd(II) complex was successfully immobilized onto modified silica support.

Scanning electron microscopy (SEM) has been utilized to determine the morphology of immobilized catalyst and SEM images are presented in Figure 2. The images show that the Pd complex on the silica surface is aggregated irregularly. EDX analysis results show that $62.67,19.9,6.36,1.04$ and $2.19 \%$ of silicon, oxygene, carbon, nitrogene and palladium are present respectively. The content of palladium metal was found to be close to the result obtained by XRF spectroscopy. 


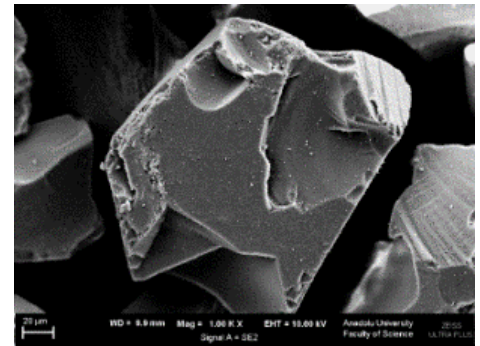

(a)

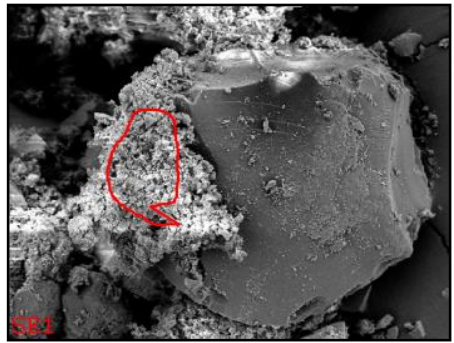

(b)

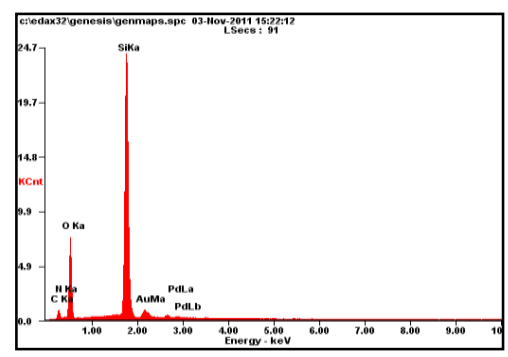

(c)

Figure 2. (a) SEM image of silica

(b) SEM image of $\mathrm{SiO}_{2}$-ThiophPd(II)

(c) EDX spectra of $\mathrm{SiO}_{2}$-ThiophPd(II)

The specific surface area obtained by the BET method for free $\mathrm{SiO}_{2}$ was found as $425.0 \mathrm{~m}^{2} / \mathrm{g}$. After the modification with APTES, the surface area reduced to $258 \mathrm{~m}^{2} / \mathrm{g}$. It was found that the surface area decreased to $134 \mathrm{~m}^{2} / \mathrm{g}$ after the immobilization of palladium complex to the surface. This reduction arise from immobilization of organic particles onto the porous silica [25]. The pore volume of silica-based catalyst $\left(\mathrm{SiO}_{2}-\mathrm{ThiophPd}(\mathrm{II})\right)$ was determined as $0.368 \mathrm{cc} / \mathrm{g}$. Also, it was found that the pore size distribution of $\mathrm{SiO}_{2}$-ThiophPd(II)) displayed multi-peaks at two different length scales: mesoporous (2$50 \mathrm{~nm})$ and microporous $(<2 \mathrm{~nm})$.

\subsection{Catalytic Hydrogenation Reactions in $\mathrm{scCO}_{2}$ Media}

Experimental procedure and equipment for hydrogenation reactions in $\mathrm{scCO}_{2}$ media have been detailed previously [24]. Three different alkenes (styrene, 1-octene and cyclohexene) were used to determine the activity of the catalyst. To determine the effect of temperature on hydrogenation of styrene, catalytic experiments were performed in the temperature range of 330 to $370 \mathrm{~K}$. These experiments were

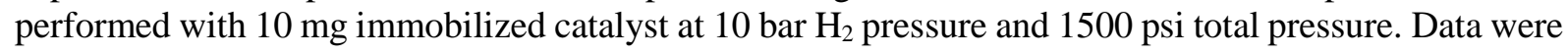
given in Table 1.

Table 1. Hydrogenation of various alkenes with $\mathrm{SiO}_{2}-\mathrm{ThiophPd}(\mathrm{II})$ in $\mathrm{scCO}_{2}$ media

\begin{tabular}{|c|c|c|c|c|c|c|}
\hline Substrate & $\mathbf{T}(\mathbf{K})$ & $\mathbf{t}(\min )$. & Product Distr.\% & Conversion \% & TON $^{\mathrm{a}}$ & TOF $\left(\mathbf{h}^{-1}\right)^{\mathbf{b}}$ \\
\hline \multirow[t]{8}{*}{ Styrene } & 320 & 120 & Ethyl benzene & 36.0 & 1585 & 793 \\
\hline & 330 & 120 & Ethyl benzene & 98.0 & 4315 & 2157 \\
\hline & 340 & 120 & Ethyl benzene & 100 & 4403 & 2202 \\
\hline & 350 & 90 & Ethyl benzene & 100 & 4403 & 2935 \\
\hline & 360 & 60 & Ethyl benzene & 100 & 4403 & 4403 \\
\hline & 370 & 45 & Ethyl benzene & 100 & 4403 & 5871 \\
\hline & 330 & 360 & $n$-octane (52.7\%), 2-octene (25.7\%), 3-octene (9.6\%) & 88.06 & 2862 & 477 \\
\hline & 340 & 360 & $n$-octane $(71.2 \%), 2$-octene $(20.8 \%), 3$-octene $(6.8 \%)$ & 98.75 & 3209 & 535 \\
\hline \multirow[t]{4}{*}{ 1-Octene } & 350 & 360 & $n$-octane (90.3), 2-octene (7.0\%), 3-octene (2.2\%) & 99.53 & 3235 & 539 \\
\hline & 360 & 360 & $n$-octane (82.6\%), 2-octene (12.1), 3-octene (4.4\%) & 99.11 & 3221 & 537 \\
\hline & 370 & 60 & $n$-octane (98.7), 2-octene (1.0), 3-octene (0.3) & 100 & 3250 & 3250 \\
\hline & 330 & 360 & Cyclohexane & 51.1 & 2553 & 425 \\
\hline \multirow[t]{3}{*}{ Cyclohexene } & 340 & 360 & Cyclohexane & 96.1 & 4801 & 800 \\
\hline & 350 & 180 & Cyclohexane & 99.6 & 4976 & 1659 \\
\hline & 390 & 120 & Cyclohexane & 100 & 4996 & 2498 \\
\hline
\end{tabular}

$\mathrm{P}_{\mathrm{T}}=1500 \mathrm{psi}, \mathrm{P}_{\mathrm{H} 2}=10 \mathrm{bar}, \mathrm{m}_{\text {cat }}=10 \mathrm{mg}, \mathrm{V}_{\text {subst }}: 100 \mu \mathrm{L},{ }^{a} \mathrm{TON}=$ mmol of product per mmol of Pd catalyst, ${ }^{\mathrm{b}} \mathrm{TOF}=\mathrm{TON} / \mathrm{time}$. 
Ethylbenzene is the main product of styrene reduction. Ethylbenzene conversion was found to be $36 \%$ for $120 \mathrm{~min}$ at $330 \mathrm{~K}$. When the temperature was increased by $10 \mathrm{~K}$, conversion increased to $98 \%$ for $120 \mathrm{~min}$. TOF value of the homogeneous catalyst (ThiophPd(II) complex) was reported in the previous work as $372 \mathrm{~h}^{-1}$ in $350 \mathrm{~K}$ temperature (Table 2). In this study, we observed that the efficiency of the catalyst increased 8 fold after being immobilized at the same temperature $\left(\mathrm{TOF}=2939 \mathrm{~h}^{-1}\right)$. The best ethylbenzene conversion in styrene hydrogenation using immobilized catalyst was obtained at $370 \mathrm{~K}$ with TOF value as $5871 \mathrm{~h}^{-1}$. The results indicated that immobilization protects the catalyst from deactivation or decomposition.

Table 2. Comparison of activity of immobilized catalyst and its homogeneous counterpart

\begin{tabular}{|c|c|c|c|c|c|c|c|c|c|c|c|c|}
\hline \multirow[b]{2}{*}{ Catalyst } & \multicolumn{4}{|c|}{ Styrene } & \multicolumn{4}{|c|}{ 1-Octene } & \multicolumn{4}{|c|}{ Cyclohexene } \\
\hline & $\begin{array}{c}\mathrm{T} \\
(\mathrm{K})\end{array}$ & $\begin{array}{c}\mathrm{t} \\
(\mathrm{min} .)\end{array}$ & $\begin{array}{c}\text { Conv. } \\
(\%)\end{array}$ & $\begin{array}{l}\text { TOF } \\
\left(\mathrm{h}^{-1}\right)\end{array}$ & $\begin{array}{c}\mathrm{T} \\
(\mathrm{K})\end{array}$ & $\begin{array}{c}\mathrm{t} \\
(\mathrm{min} .)\end{array}$ & $\begin{array}{c}\text { Conv. } \\
(\%)\end{array}$ & $\begin{array}{l}\text { TOF } \\
\left(\mathrm{h}^{-1}\right)\end{array}$ & $\begin{array}{c}\mathrm{T} \\
(\mathrm{K})\end{array}$ & $\begin{array}{c}\mathrm{T} \\
(\mathrm{min} .)\end{array}$ & $\begin{array}{c}\text { Conv. } \\
(\%)\end{array}$ & $\begin{array}{l}\text { TOF } \\
\left(\mathrm{h}^{-1}\right)\end{array}$ \\
\hline SCOOPd & 350 & 30 & 90 & 372 & 350 & 180 & 63 & 52 & 350 & 180 & 0 & 0 \\
\hline Si-SCOOPd & 350 & 90 & 100 & 2939 & 350 & 360 & 99.5 & 539 & 350 & 180 & 99.6 & 1659 \\
\hline & 370 & 45 & 100 & 5871 & 370 & 60 & 100 & 3250 & 390 & 120 & 100 & 2498 \\
\hline
\end{tabular}

$\mathrm{P}_{\mathrm{T}}=1500 \mathrm{psi}, \mathrm{P}_{\mathrm{H} 2}=10$ bar

To examine the effect of hydrogen pressure on the catalytic hydrogenation of styrene, experiments were carried out four different $\mathrm{H}_{2}$ pressure range between 5-20 bar. As seen in Figure 3, the highest TOF value was obtained at 10 bar $\mathrm{H}_{2}$ pressure. No significant differences were observed in other pressures.

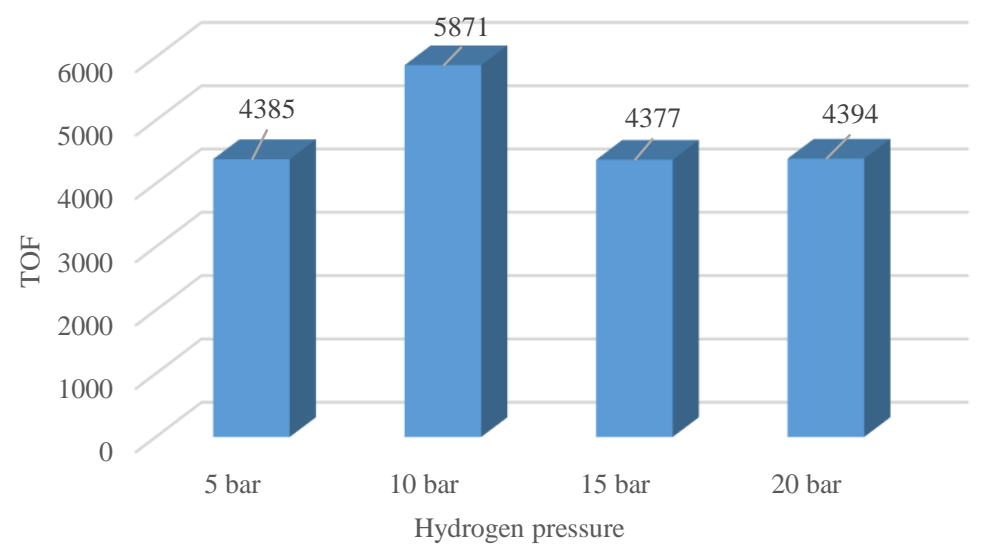

Figure 3. $\mathrm{H}_{2}$ pressure effect in styrene hydrogenation $\left(\mathrm{T}=370 \mathrm{~K}, \mathrm{P}_{\mathrm{T}}=1500 \mathrm{psi}, \mathrm{m}_{\text {cat }}=10 \mathrm{mg}, \mathrm{V}_{\text {subst }}\right.$ : $\left.100 \mu \mathrm{L}\right)$

We also studied four different substrate volume (0.0087-0.0609 $\mathrm{M}$ range) to determine the effect of substrate concentration in styrene hydrogenation. Experiments were performed at $370 \mathrm{~K}, 10$ bar $\mathrm{H}_{2}$ pressure, and 1500 psi total pressure. The activity of immobilized catalyst decreased linearly with increasing substratee concentration (Fig 4). This can be explained by the fact that the number of active centers on solid support is less than that of increasing substratee molecules in reaction media. 


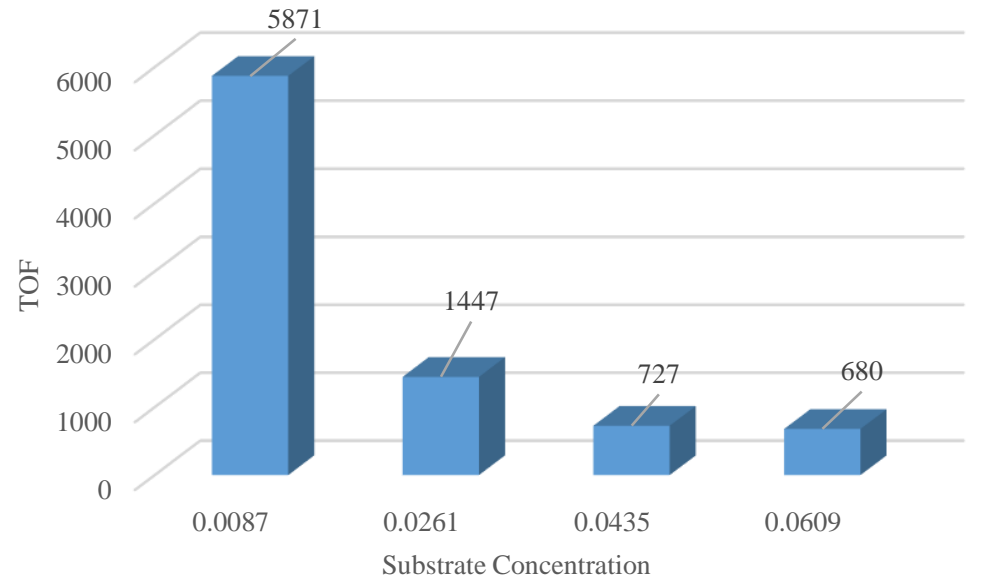

Figure 4. Substrate concentration effect in styrene hydrogenation $\left(\mathrm{T}=370 \mathrm{~K}, \mathrm{P}_{\mathrm{H} 2}=10 \mathrm{bar}, \mathrm{P}_{\mathrm{T}}=1500 \mathrm{psi}, \mathrm{m}_{\mathrm{cat}}=10 \mathrm{mg}\right)$

1 -octene is a linear alkene including a double bond at the alpha position and reduced to $n$-octane when hydrogenated. Also, some isomerization products of 1-octene such as 2-octene and 3-octene can be obtained during the hydrogenation process. Hydrogenation of 1-octene was performed between 330-370 $\mathrm{K}$ to determine temperature effect on catalytic activity. Conversion increased from $88.06 \%$ to $99.5 \%$ when the temperature changed from $330 \mathrm{~K}$ to $350 \mathrm{~K}$. It was also observed that the amounts of isomerization products were higher at lower temperatures. Total product conversion with homogeneous catalyst was reported as $63 \%$ (with TOF $=52 \mathrm{~h}^{-1}$ ) at $350 \mathrm{~K}$ for $180 \mathrm{~min}$. We obtained $99.5 \%$ total conversion and $82.6 \% n$-octane selectivity with immobilized catalyst at same temperature (with TOF = $539 \mathrm{~h}^{-1}$ ). The results showed that the effectivity of immobilized catalyst is about 10 times more than the homogeneous form in the same reaction conditions. $100 \% n$-octane selectivity was obtained with

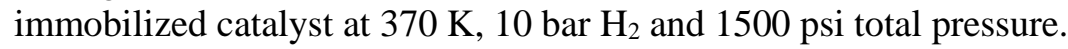

Cyclohexene is an internal alkene with a $\pi$ bond in the cyclic ring. It is difficult to reduce this isolated $\pi$ bond than delocalized $\pi$ bonds. The hydrogenation of cyclohexene in the presence of a catalyst yields cyclohexane major product. In our catalytic system, cyclohexene hydrogenated to cyclohexane with $99.6 \%$ conversion value in $180 \mathrm{~min}$ at $350 \mathrm{~K}$ temperature. This conversion value is much higher than conversion obtained by homogeneous counterpart. $1.8 \%$ cyclohexane conversion with homogeneous catalyst was obtained at the same conditions. The highest cyclohexane conversion as $100 \%$ was obtained when the temperature was increased to $390 \mathrm{~K}$ for $2 \mathrm{~h}$.

The order of activity of immobilized catalyst in the alkene hydrogenation was determined as styrene > cyclohexene >1-octene at same temperature. This order was different from the non-immobilized counterpart previously reported. The low activity in 1-octene hydrogenation may be explained based on steric effect of long carbon chain. Steric effect reduces catalyst-substrate interaction. Therefore, 1-octene reactivity was found to be lower.

One of the objectives of this work is to show usage of $\mathrm{scCO}_{2}$ as an alternative reaction solvent in both synthesis and catalytic reactions. For this reason, we also investigated the effectivity of immobilized catalyst in traditional organic solvent to compare solvent effect on catalytic activity. The reaction conditions are the same with in $\mathrm{scCO}_{2}$ media where the highest conversions obtained. As seen in Table 3 , styrene hydrogenation did not effected by solvent exchange. In 1-octene hydrogenation, the best catalytic activity was obtained in methanol and $\mathrm{scCO}_{2}$. The activity of immobilized catalyst decreased almost to half in hexane. Solvent was found to be most effective on the cyclohexene hydrogenation. In the cyclohexene hydrogenation, efficiency order of the solvents was determined as $\mathrm{scCO}_{2}>$ hexane> methanol. These results indicate that $\mathrm{scCO}_{2}$ may be preferred instead of harmful organic solvents. The 
easy removal of $\mathrm{scCO}_{2}$ from the reaction medium facilitates the recovery of the catalyst and furthermore eliminates the purification problem of the products.

Tablo 3. Comparison of the activities of catalyst in $\mathrm{scCO}_{2}$ and organic solvent media

\begin{tabular}{|c|c|c|c|c|c|c|c|c|c|c|c|c|}
\hline \multirow[b]{2}{*}{ Solvent } & \multicolumn{4}{|c|}{ Styrene } & \multicolumn{4}{|c|}{ 1-Octene } & \multicolumn{4}{|c|}{ Cyclohexene } \\
\hline & $\begin{array}{c}\mathrm{T} \\
(\mathrm{K})\end{array}$ & $\begin{array}{c}\mathrm{t} \\
(\mathrm{min} .)\end{array}$ & $\begin{array}{c}\text { Conv. } \\
(\%)\end{array}$ & $\begin{array}{l}\text { TOF } \\
\left(h^{-1}\right)\end{array}$ & $\begin{array}{c}\mathrm{T} \\
(\mathrm{K})\end{array}$ & $\begin{array}{c}\mathrm{t} \\
(\mathrm{min} .)\end{array}$ & $\begin{array}{c}\text { Conv. } \\
(\%)\end{array}$ & $\begin{array}{l}\text { TOF } \\
\left(h^{-1}\right)\end{array}$ & $\begin{array}{c}\mathrm{T} \\
(\mathrm{K})\end{array}$ & $\begin{array}{c}\mathrm{t} \\
(\mathrm{min} .)\end{array}$ & $\begin{array}{c}\text { Conv. } \\
(\%)\end{array}$ & $\begin{array}{l}\text { TOF } \\
\left(h^{-1}\right)\end{array}$ \\
\hline $\mathrm{scCO}_{2}$ & 370 & 45 & 100 & 5871 & 370 & 60 & 100 & 3250 & 350 & 180 & 99.6 & 1659 \\
\hline Methanol & 370 & 45 & 100 & 5871 & 370 & 90 & 100 & 2166 & 350 & 180 & 11 & 183 \\
\hline Hexane & 370 & 45 & 100 & 5871 & 370 & 120 & 100 & 1625 & 350 & 180 & 50 & 832 \\
\hline
\end{tabular}

Immobilization of a homogeneous catalyst on support material provide higher activity/selectivity and easily separation of catalyst from reaction media. Furthermore, immobilized catalysts can be reused many times without a reduction in its catalytic activity. For this reason, we have examined the reusability of the immobilized catalyst in styrene hydrogenation. Blank tests were firstly done in the recycle tests. Experiments were started with the fresh substratee (without catalyst) every time. After being sure that the reactor was clean, new cycle experiments were started with recovered catalyst. At the end of the each recycle reaction, the heterogeneous catalyst was washed several times with methanol and acetone and dried by vacuum before using. As shown in Figure 5, immobilized homogeneous catalyst remains stable during 10 cycles. The conversion started to decrease by $0.3 \%$ after the 6th cycle. In the 10th cycle, it was determined that only $0.4 \%$ reduction in catalyst activity. We recently reported that the activity of heterogenized $\mathrm{Rh}(\mathrm{I})$ catalyst bearing the same ligand decreased by $15 \%$ at the end of the tenth [26]. This shows that the palladium metal retains its activity for a longer time than the rhodium metal.

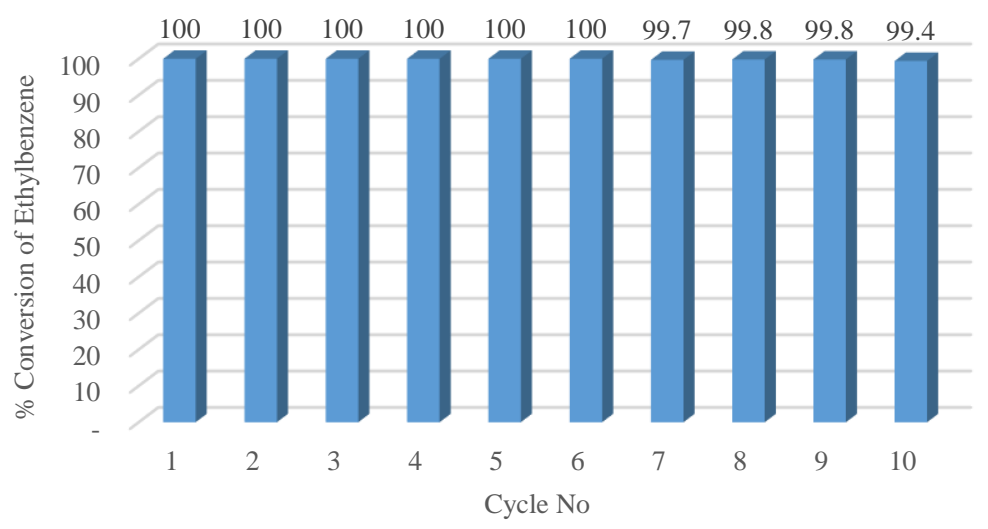

Figure 5. Recycle of immobilized catalyst in styrene hydrogenation (Reac. cond. $\mathrm{T}=370 \mathrm{~K}, \mathrm{P}_{\mathrm{H} 2}=10 \mathrm{bar}, \mathrm{P}_{\mathrm{T}}=102$ bar, $\mathrm{m}_{\mathrm{kat}}=10$ $\mathrm{mg}, \mathrm{V}_{\text {subst: }}: 100 \mu \mathrm{L}, \mathrm{n}_{\mathrm{s}} / \mathrm{n}_{\mathrm{k}}=4403$

\section{CONCLUSION}

In this work, we have combined the advantage of heterogeneous catalysis and $\mathrm{scCO}_{2}$ media. The immobilized catalyst has higher activity and selectivity then homogeneous counterpart. Immobilized catalyst $\left(\mathrm{SiO}_{2}\right.$-ThiophPd(II)) was eight times more active than ThiophPd(II) complex in styrene hydrogenation. Also, it was found that immobilized catalyst can be reused at least 10 times with a negligible loss in its activity. We previously reported synthesis and catalytic activity of immobilized $\mathrm{Rh}$ (I) catalyst [26]. When two studies are compared, the efficiency of the immobilized Pd(II) catalyst for each of the three alkenes was found higher than immobilized Rh(I) catalyst. It is indicated that the Pd metal has more effect on the activity of the catalyst. The best activity was obtained in cyclohexene 
hydrogenation reaction. While homogeneous counterpart (ThiophPd(II)) did not show activity, high cyclohexane conversion were obtained with $\mathrm{SiO}_{2}$-ThiophPd(II) catalyst. The high activity of immobilized catalyst can be attributed to sufficient accessibility of the active centre of catalyst for the reactants and efficient stabilization of the homogeneous catalyst on the silica surface. $\mathrm{SiO}_{2}-\mathrm{ThiophPd}(\mathrm{II})$ can be reused without loss of activity after at least 10 reaction cycles in styrene hydrogenation. We also demostrate that the $\mathrm{scCO}_{2}$ can be use efficiently in the synthesis of catalyst and catalytic hydrogenation reactions as sustainable green solvent.

\section{ACKNOWLEDGEMENTS}

We thank to the Anadolu University Plant Drug and Scientific Research Center (AUBIBAM) for NMR measurements and also Anadolu University Commission of Scientific Research Projects for financial support (Project No. 1101F010).

\section{REFERENCES}

[1] Mehendale NC, Bezemer C, Walree CA Van, et al. Novel silica immobilized NCN-pincer palladium ( II ) and platinum ( II ) complexes : Application as Lewis acid catalysts. 2006; 257:167175.

[2] Jessop PG, Heldebrant DJ. Green Biphasic Homogeneous Catalysis. ChemInform 2006; 37(35):627-648.

[3] Mäki-Arvela P, Hájek J, Salmi T, et al. Chemoselective hydrogenation of carbonyl compounds over heterogeneous catalysts. Appl Catal A Gen 2005; 292:1-49.

[4] Cornils B, Herrmann WA. Concepts in homogeneous catalysis : the industrial view. 2003; 216:2331.

[5] Corma A, Garcia H. Silica-bound homogenous catalysts as recoverable and reusable catalysts in organic synthesis. Adv Synth Catal 2006; 348:1391-1412.

[6] Wang Z, Ding K, Uozumi Y. An Overview of Heterogeneous Asymmetric Catalysis. In: Handbook of Asymmetric Heterogeneous Catalysis. 2008; pp. 1-24.

[7] Merckle C, Blümel J. Improved Rhodium Hydrogenation Catalysts Immobilized on Oxidic Supports. Adv Synth Catal 2003; 34:5-15.

[8] Margelefsky EL, Zeidan RK, Davis ME. Cooperative catalysis by silica-supported organic functional groups. Chem Soc Rev 2008; 37:1118-1126.

[9] Jannes G. Supported homogeneous catalysts. Appl Catal 1985; 14(2):394.

[10] Thomas JM, Raja R. Catalytic significance of organometallic compounds immobilized on mesoporous silica: Economically and environmentally important examples. J Organomet Chem 2004; 689:4110-4124.

[11] Dioos BML, Vankelecom IFJ, Jacobs PA. Aspects of immobilisation of catalysts on polymeric supports. Adv Synth Catal 2006; 348:1413-1446.

[12] Hauthal WH. Advances with supercritical fluids [ review ]. Chemos 2001; 43:123-35. 
[13] Sheldon RA. Green solvents for sustainable organic synthesis: state of the art. Green Chem 2005; 7:267-278.

[14] Mizuuchi H, Jaitely V, Murdan S, et al. Room temperature ionic liquids and their mixtures: Potential pharmaceutical solvents. Eur J Pharm Sci 2008; 33:326-31.

[15] Pozzi G, Cavazzini M, Cinato F, et al. Enantioselective catalysis in fluorinated media - Synthesis and properties of chiral perfluoroalkylated (salen)manganese complexes. European J Org Chem 1999; (8):1947-1955.

[16] Kankala RK, Zhang YS, Wang S, et al. Supercritical Fluid Technology: An Emphasis on Drug Delivery and Related Biomedical Applications. Adv Heal Mater 2017; 6:2-31.

[17] Budisa N, Schulze-makuch D. Supercritical Carbon Dioxide and Its Potential as a Life-Sustaining Solvent in a Planetary Environment. Life 2014; 4:331-340.

[18] Leitner W. Supercritical carbon dioxide as a green reaction medium for catalysis. Acc Chem Res 2002; 35(9):746-756.

[19] Rajagopalan B, Wei M, Musie GT, et al. Homogeneous catalytic epoxidation of organic substrates in $\mathrm{CO}_{2}$-expanded solvents in the presence of water-soluble oxidants and catalysts. Ind Eng Chem Res 2003; 42(25):6505-6510.

[20] Wang X, Kawanami H, Dapurkar SE, et al. Selective oxidation of alcohols to aldehydes and ketones over TiO2-supported gold nanoparticles in supercritical carbon dioxide with molecular oxygen. Appl Catal A Gen 2008; 349:86-90.

[21] Wu W, Li W, Han B, et al. Effect of organic cosolvents on the solubility of ionic liquids in supercritical $\mathrm{CO}_{2}$. J Chem Eng Data 2004; 49:1597-1601.

[22] Zhang X, Heinonen S, Levanen E. Applications of supercritical carbon dioxide in materials processing and synthesis. RSC Adv 2014; 4:61137-61152.

[23] Cooper BAI. Porous Materials and Supercritical Fluids. Adv Mater 2003; 15(13):1049-1059.

[24] Yilmaz F, Mutlu A, Unver H, et al. Hydrogenation of olefins catalyzed by Pd(II) complexes containing a perfluoroalkylated S,O-chelating ligand in supercritical $\mathrm{CO} 2$ and organic solvents. J Supercrit Fluids 2010; 54(2):202-209.

[25] Sharma RK, Mishra M, Sharma S, et al. Zinc ( II ) complex immobilized on amine functionalized silica gel : a novel, highly efficient and recyclable catalyst for multicomponent click synthesis of 1,4-disubstituted 1,2,3-triazoles. J Coord Chem Taylor \& Francis 2016; 69:1152-1165.

[26] F Yilmaz, Y Karaağaç İK. Heterogenization of Homogeneous Perfluorothiophene Rh(I) Complex And Examination of Hydrogenation Activity in scCO2 Media. Anadolu Univ J Sci Technol A Appl Sci Eng 2017. 